\title{
Population of Tuta absoluta and natural enemies after releasing on tomato grown greenhouse in Turkey
}

\author{
Sevcan Öztemiz \\ Biological Control Research Station, 01321 Adana-Turkey. E-mails: s_oztemiz@hotmail.com, \\ sevcanztemiz@yahoo.com. Tel: +90-322-3441784-176. Fax: +90-322-3441702.
}

Accepted 21 February, 2013

\begin{abstract}
The study was conducted to evaluate the population of tomato leafminer, Tuta absoluta (Meyrick) (Lepidoptera: Gelechiidae) and efficiency of natural enemies on tomato grown greenhouse in Mediterranean Region of Turkey during 2010 and 2011. Trichogramma evanescens Westwood (Hymenoptera: Trichogrammatidae) and Nesidiocoris tenuis (Reuter) (Hemiptera: Miridae) were used for biological control of the pest. Both the egg parasitoid and preadatory bug were released alone and combined. The decrease of egg and larva numbers of $T$. absoluta were higher in plots released $T$. evanescens with $\boldsymbol{N}$. tenuis together than each one released separately. However, the decrease of eggs was higher than larvae in plots released $\boldsymbol{N}$. tenuis and $T$. evanescens alone. Population of $T$. absoluta and fruit numbers were influenced by the treatments. The number of fruit directly affected negatively by increasing the population density of $T$. absoluta. The trial demonstrated that it was necessary to establish $N$. tenuis population at the starting of the crop season with Ephestia kuehniella Zeller (Lepidoptera: Pyralidae) eggs, atleast two or three weeks ago, and together with parasitoid release, had a better significant reduction of $T$. absoluta population to reach maximum number of fruits.
\end{abstract}

Key words: Greenhouse, tomato, biological control, Tuta absoluta, Trichogramma evanescens, Nesidiocoris tenuis.

\section{INTRODUCTION}

Recently, Tuta absoluta has spread very quickly in Turkey, as well as in Mediterranean countries. Tuta absoluta first reported in Turkey in 2009 (Kilic, 2010), and is now posing a serious threat on tomato production. Tomato plants may be attacked at any development stage from seedlings to mature plants. The potential damage could lead up to $100 \%$ yield loss without control measure (EPPO, 2005). Larvae feed between the epidermal layers on leaves, causing irregular mines. This mining protects the larvae from getting in contact with insecticides and decreases the effects of chemical control. So, an alternative management approach is urgently needed. One possible solution is the use of biological control agents. More than 20 species of parasitic wasps have been described for $T$. absoluta (Luna et al., 2007).

One of them is the egg parasitoid Trichogramma species (Medeiros et al., 2006). Trichogramma species are the most widely used as biocontrol agents in the world and they are effective against lepidopteran eggs such as the lifeminer, T. absoluta.

Furthermore, several species of predators have been evaluated as biological control agents mainly the mirid bugs Nesidiocoris tenuis (Reuter) and Macrolophus pygmaeus (Rambur) (Urbaneja et al., 2009). Both nymph and adult stages of $N$. tenuis are prey on $T$. absoluta eggs and larval stages. It is also able to feed on the plants when the prey population is low and Nesidiocoris population is high. T. absoluta population and natural enemies with efficacy of these biological control agents after releasing are unknown in our country. The objective of the study is to evaluate the population of $T$. absoluta as well as $T$. evanescens and $N$. tenuis after releasing against pest on greenhouse-grown tomato of Mediterranean Region, Turkey. The preliminary results are presented in the study. 


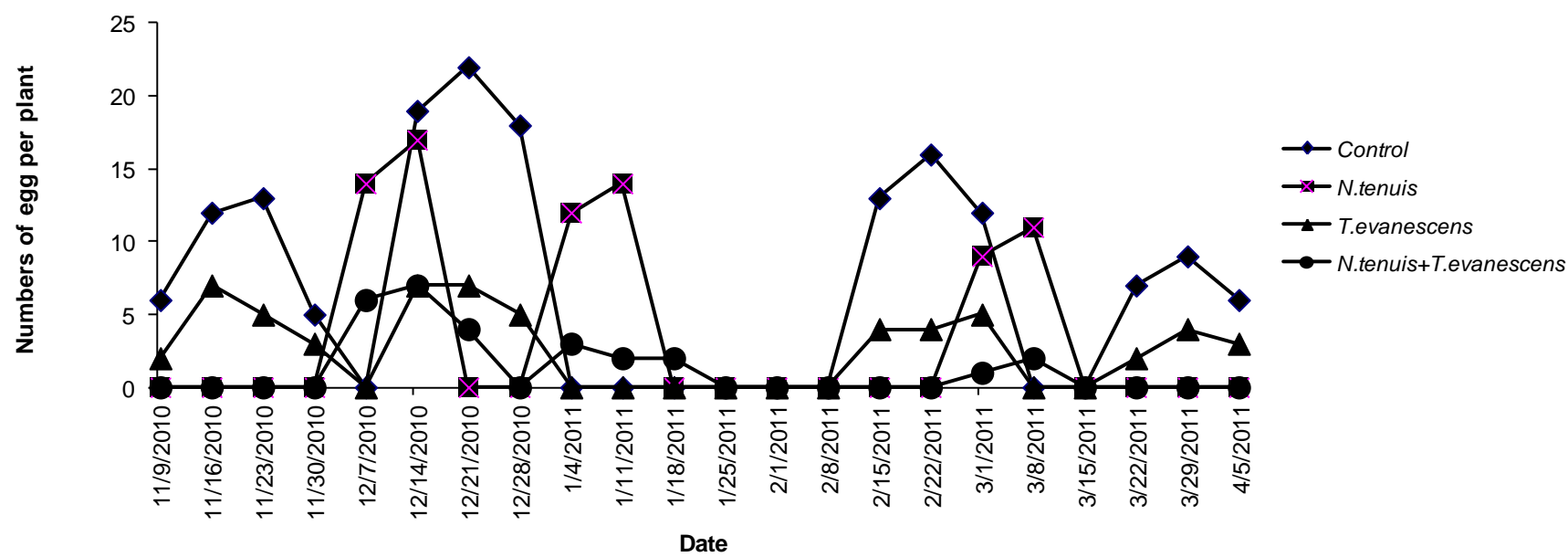

Figure 1. The population of Tuta absoluta egg on tomato plants counted in a greenhouse according to the treatments (releasing of $T$. evanescens and $N$. tenuis alone or combined together and control).

\section{MATERIALS AND METHODS}

\section{Insects rearing}

The individuals of $T$. absoluta used in the trials were obtained from a laboratory rearing on tomato plants in Biological Control Research Station, Adana, Turkey. The rearing of $T$. evanescens, also in the laboratory, as alternative host, according to the methodology described by Hassan (1981). Nesidiocoris tenuis used in the bioassay was obtained from commercial rearing (Koppert Antalya,Turkey).

\section{Greenhouse bioassay}

To evaluate the population of $T$. absoluta and efficacy of $T$. evanescens and $N$. tenuis on greenhouse of Turkey, between October and March of 2010 to 2011,12 cages $\left(10 \mathrm{~m}^{2}\right)$ were placed into the greenhouse with 24 tomato plants (Buffalo variety, commercially grown) per cage (Cabello et al., 2009). Tomato plants were transplanted in October. The experimental design was at "randomized complete blocks" with three replicates. There were four treatments: release of $T$. evanescens alone (RT), release of $N$. tenuis alone $(\mathrm{RN})$, releases of T.evanescens combined with $N$. tenuis (RTN) and control (C) (no release of any biological control agent). Each treatment was replicated three times including twelve experimental cages. Plants were infested with $T$. absoluta (two adults plant $^{-1}$ ) when tomato plants were three or four leaf stage in all cages. A total of seven releases of $T$. evanescens (75 adults' $\mathrm{m}^{-2}$ in each release) were conducted every three or four days on six cages (Cabello et al., 2009). N. tenuis was released (two individuals $\mathrm{m}^{-2}$ in each release) two times in two weeks interval in November in three cages before the pest infestation about three weeks early. Because the mirids need a long time to establish well in the crops (Calvo et al., 2010). E. kuehniella eggs were given as a food source. The other three cages were leaved as a control. Cultivation practices were normally used in tomato greenhouse. The numbers of egg and larva of $T$. absoluta were counted once a week until harvest. Five plants in each plot selected were counted for sampling. Besides, number of fruit was counted in each plot at harvest. Data on number of pest and fruit number were submitted to the variance and correlation analyses (ANOVA) (Zar, 1999) and these averages compared by the LSD (Least Significant Difference) test (Fischer, 1954; Zar, 1999) at 1\% of probability error.

\section{RESULTS AND DISCUSSION}

Compared with the control plots, the decrease of egg numbers of $T$. absoluta was higher in plots RTN than RN (Figure 1). Similarly, result was also obtained from the larval stage of the pest (Figure 2). Although the decrease of eggs and larva of $T$. absoluta had similar results in the plots RTN, the decrease of eggs of the pest was higher than larvae in plots RN and RT.

The first parasitized eggs were seen on 9 November in the plots RT, but the parasitized eggs were seen late (on 7 December) in the plots RTN (Figure 3).

The parasitation was related with egg population of the pest and reached its highest level at the end of February in the plots RT. Although, the numbers of egg were lower in the plots RTN, parasitation was found to be higher than that of the released parasitoid alone (Figure 3). Because $N$. tenuis preferred egg stage and preyed actively on $T$. absoluta eggs. The decrease of eggs was higher than larvae in the plots RN. Similarly result reported by Arno et al. (2009) that $N$. tenuis is important predator of $T$. absoluta eggs than that of larvae.

The population of predatory bug was lower in plots where $N$. tenuis combined with parasitoid than that of the released alone (Figure 4). Predatory population were recorded at varying levels throughout the vegetation period of tomatoes, from November to April, which reached the peak level in the second part of December in both plots where released alone and combined with parasitoid. Because $N$. tenuis preyed on not only $T$. absoluta eggs but also all larval stages, especially firstinstar larvae. Besides, predatory bug has a shorter life cycle (on tomato, about two weeks) when it feeds on eggs or larvae of moth. 


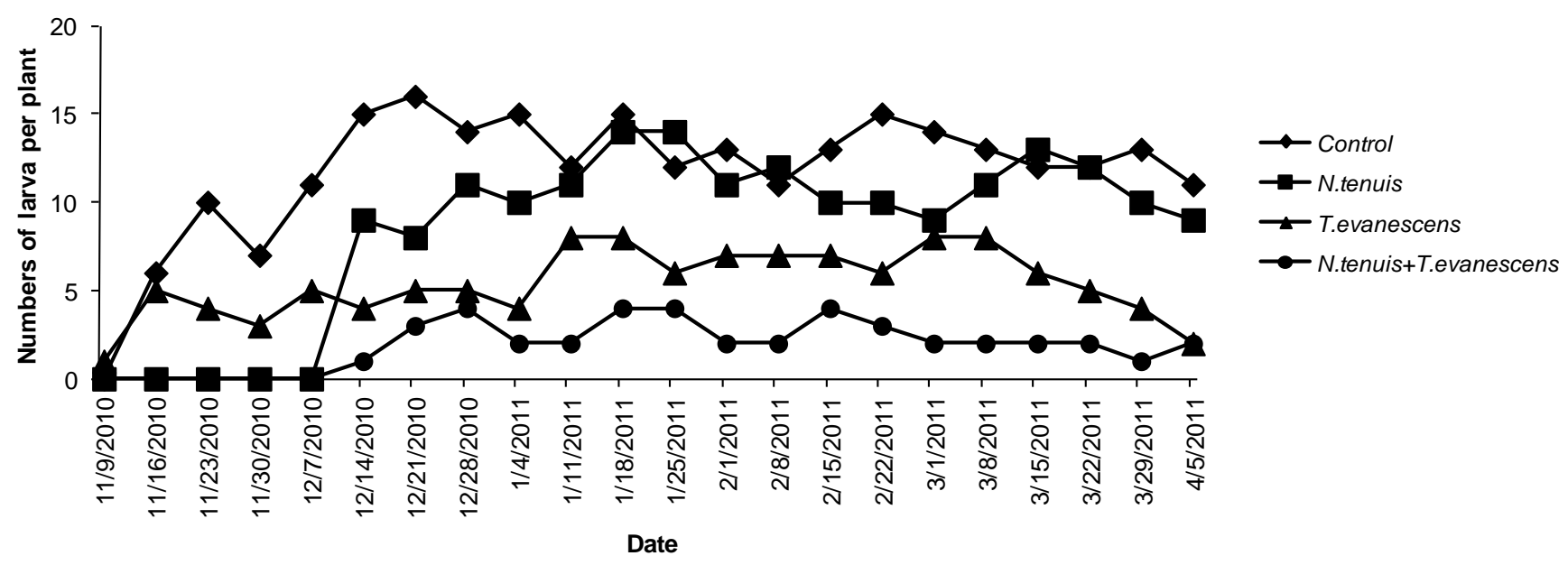

Figure 2. The population of Tuta absoluta larva on tomato plants counted in a greenhouse according to the treatments (releasing of $T$. evanescens and $N$. tenuis alone or combined together and control).

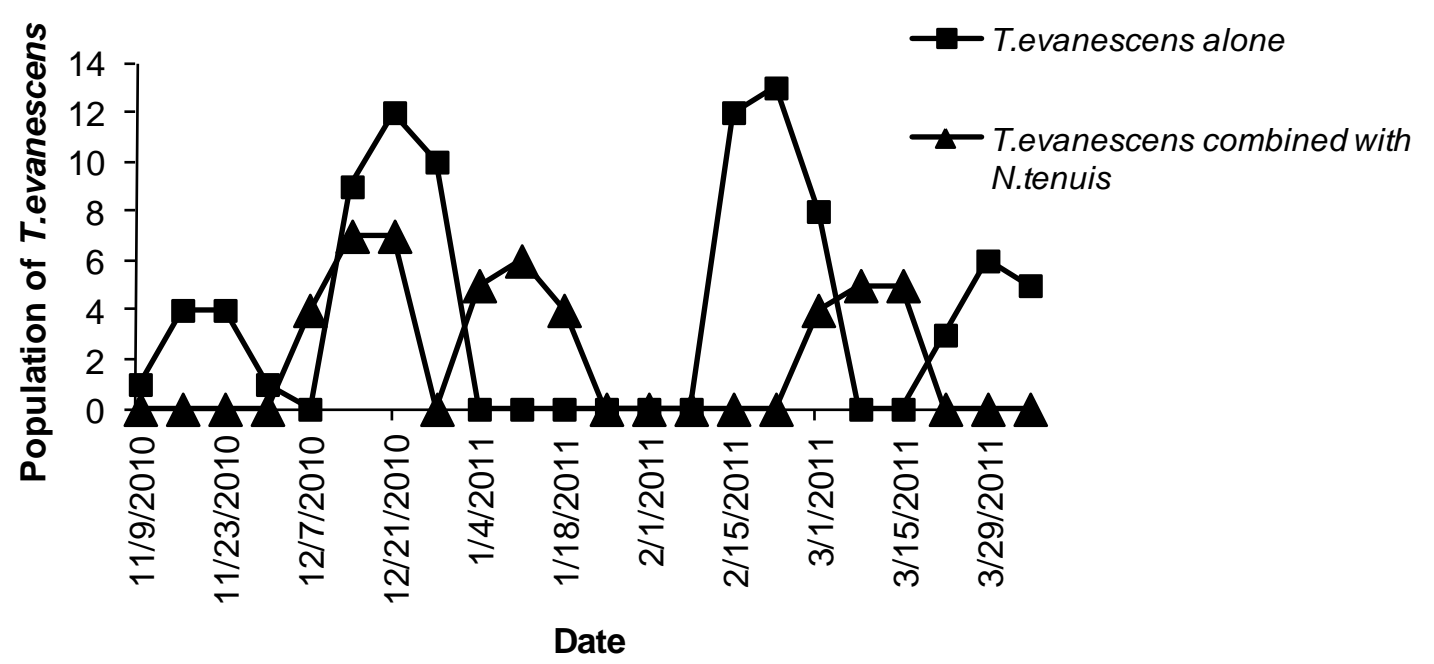

Figure 3. Population of $T$. evanescens by releasing alone and combined with $N$. tenuis.

The study shows that $N$. tenuis did not cause damage on tomato plants because of low population and had a prey. Eggs of E. kuehniella were provided as prey in the study. This prey was proven a high quality food resource for the predator population (Urbaneja et al., 2005).

However, tomato grown in greenhouses, damage occurs when population of $N$. tenuis is high (100 or more bugs per plant) and if the pest population is low or no prey available. To estimate the pest population in the crop accurately to introduce the predatory bug is very important. The population densities of $N$. tenuis were related to the damage incidence on the plants. It was found that the highest damage incidence was obtained when $3 \mathrm{~N}$. tenuis individuals per leaf occurred in a period when the number of the pest had been low (Perdikis et. al., 2009). Sanches (2008) reported that the maximum average population density of $N$. tenuis was about 5 individuals per tomato leaf. The peak densities of $N$. tenuis individuals per plant in tomato grown in greenhouse and open field crops were ranged at similar levels (Arno et al., 2006). These different conclusions among studies might be due to the different experimental material used, such as the tomato varieties, $N$. tenuis populations originating from different geographical areas and factors such as temperature, humidity and day length. As stated by Sanchez (2008), the number of necrotic rings was closely correlated with temperature increase from 20 to $30^{\circ} \mathrm{C}$. However, in this study average temperature was mostly kept at levels lower than $30^{\circ} \mathrm{C}$. Thus, further studies should be conducted for the 


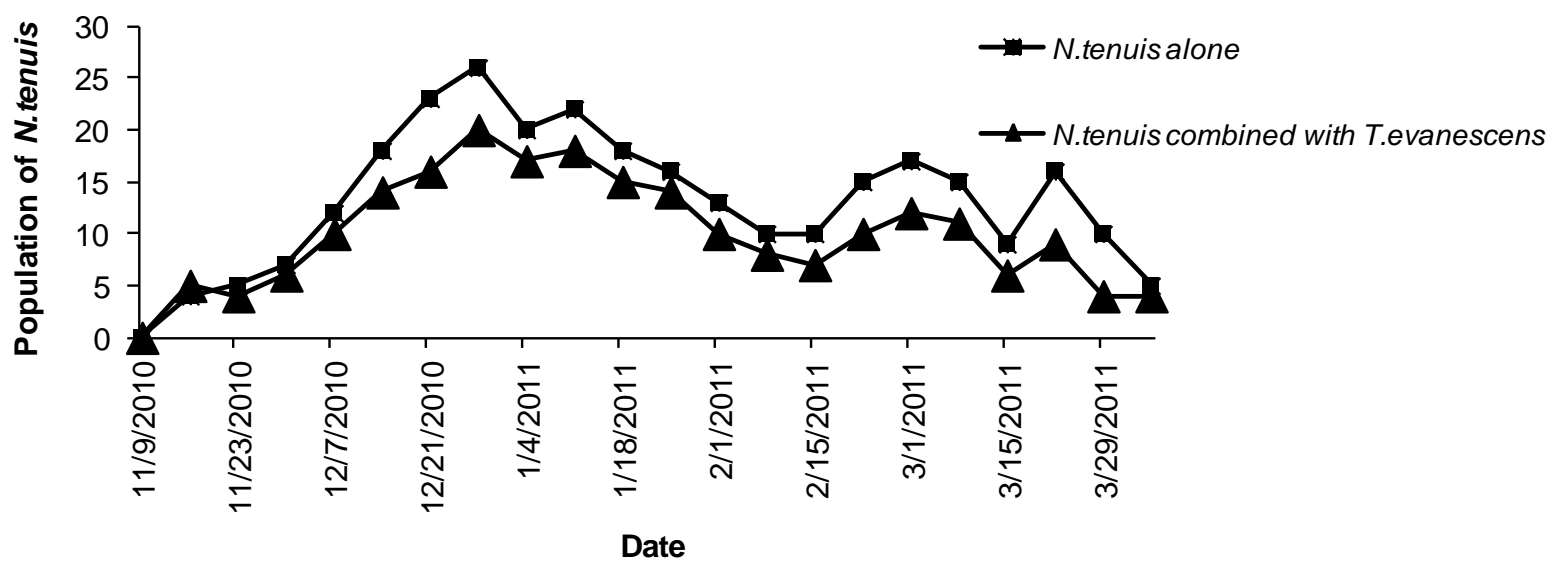

Figure 4. Population of $N$. tenuis by releasing alone and combined with $T$. evanescens.

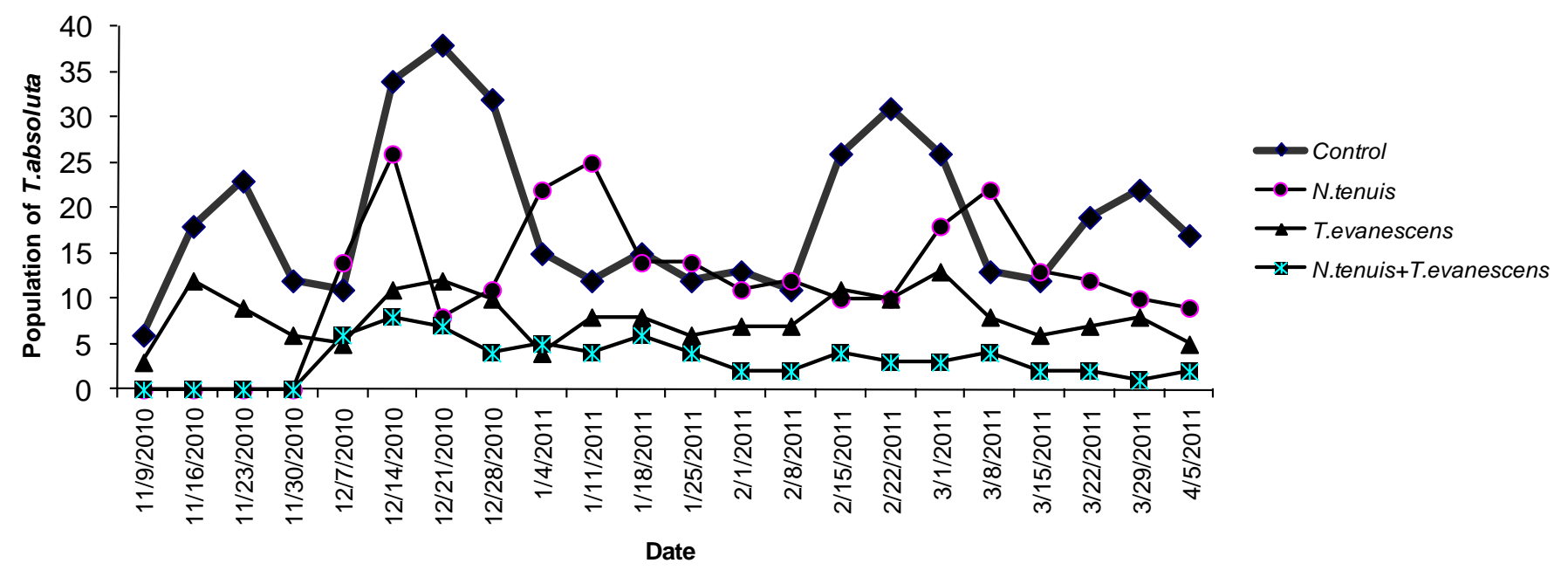

Figure 5. The population of Tuta absoluta on tomato plants counted in a greenhouse according to the treatments (releasing of $T$. evanescens and $N$. tenuis alone or combined together and control).

evaluation of temperature and likely other abiotic factors, on flower abortion and fruit number by $N$. tenuis.

The results demonstrated that it was necessary to establish $N$. tenuis population at the starting of the crop season, at least two or three weeks ago, and to release together with parasitoid, had a better significant reduction of $T$. absluta (Figures 5 and 6 ).

Gabarra and Arno (2010) reported that the pest incidence was lower when biological control strategies based on the use of polyphagous predators (Macrolophus pygmaeus and Nesidiocoris tenuis) were applied instead of conventional chemical control.

The low population of $T$. absoluta was remarkable in the RTN plots comparing with control plots. It is clear that the host eggs and larvae have been destroyed by the parasitoids and predators. The most reduction of the host eggs was observed in the RTN plots and followed by the
RT and RN plots (Figure 6). The number of $T$. absoluta and number of fruits developed on the plants were influenced by the treatment $(F=90.9, \mathrm{LSD}=80.98$, d.f. $=$ $11, p<0.01)$. The minimum number of the pest and maximum number of fruits were observed when releasing both biological control agents together.

In the research, the number of fruit directly affected negatively by increasing of population density of $T$. absoluta $\left(r=-0.990^{* *}\right)$ (Table 1$)$.

In this study, it was found that $T$. absoluta had three or four generations in a greenhouse of tomato production in autumn-winter period. Undoubtedly, the pest had more generation during spring and summer than in autumn and winter because of the climatic conditions. The effect of climate change had a significant effect on number and duration of generations of $T$. absoluta (CABI, 2007; EPPO, 2005). N. tenuis has a low potential in the change 


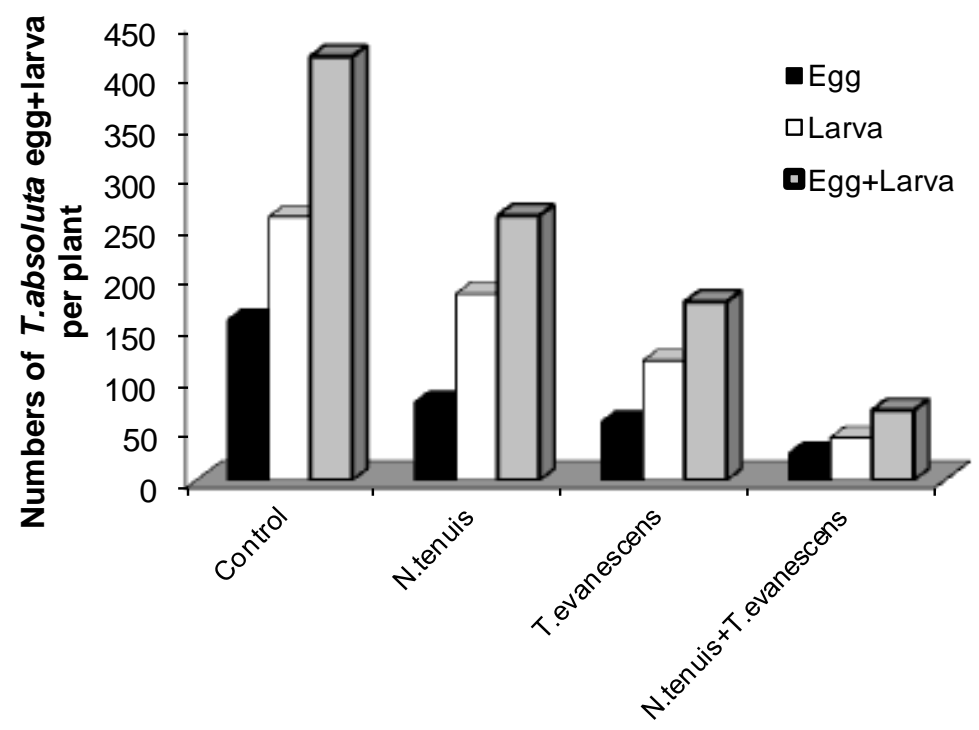

Treatments

Figure 6. The numbers of Tuta absoluta per tomato plant counted in a greenhouse according to the treatments (releasing of $T$. evanescens and $N$. tenuis alone or combined together and control).

Table 1. Mean ( $\pm S E)$ number of fruit and $T$. absoluta in greenhouse-grown tomatoes following the release of the parasitoid $T$. evanescens alone, the predator $N$. tenuis alone, and combined release of both agents and control, Turkey.

\begin{tabular}{lcc}
\hline Treatment $^{\star}$ & Number of $\boldsymbol{T}$. absoluta & Number of fruit \\
\hline N. tenuis & $261 \pm 14.73^{\mathrm{b}}$ & $410 \pm 11.71^{\mathrm{b}}$ \\
T.evanescens & $176 \pm 20.29^{\mathrm{c}}$ & $486 \pm 23.45^{\mathrm{b}}$ \\
N. tenuis + T.evanescens & $69 \pm 6.11^{\mathrm{d}}$ & $649 \pm 22.57^{\mathrm{a}}$ \\
Control & $418 \pm 8.50^{\mathrm{a}}$ & $144 \pm 10.39^{\mathrm{c}}$ \\
\hline
\end{tabular}

*Means within a column followed by the different lower case letter are significantly different (LSD, $p<0.01$ ).

records on tomato plants because of low population in the study.

Therefore, it could be considered as a beneficial predator at least which occurs at densities similar to those used in the study. However, further studies should search its damage potential in different population densities at the growth stage of tomato plants, in the protected crops of the Mediterranean region of Turkey. However, factors stimulating population densities of both pest and natural enemies should be considered while designing IPM programs for tomato leafminer.

\section{REFERENCES}

Arno J, Castañé C, Riudavets J, Roig J, Gabarra R (2006). Characterization of damage to tomato plants produced by the zoophytophagous predator, Nesidiocoris tenuis. IOBC/WPRS Bull. 29 (4): 249-254.
Arno J, Sorribas R, Prat M, Montse M, Pozo C, Rodriguez D, Garreta A, Go'mez A, Gabarra R (2009). Tuta absoluta, a new pest in IPM tomatoes in the Northeast of Spain. IOBC/WPRS Bull. 49:203-208.

Cabello T, Gallego JR, Vila E, Soler A, Del Pino M, Carnero A, Herna'ndez-Sua'rez E, Polaszek A (2009). Biological control of the South American tomato pinworm. Tuta absoluta (Lep.: Gelechiidae), with releases of Trichogramma achaeae (Hym.: Trichogrammatidae) in tomato greenhouses of Spain. IOBC/WPRS Bull. 49:225-230.

CABI (2007). Crop Protection Compendium. http://www.cabicompendium.org.

Calvo FJ, Belda JE, Gime'nez A (2010). A new strategy for biological control of white fly and Tuta absoluta in tomato. Phytoma España. 216:46-52.

EPPO (2005). Tuta absoluta. OEPP/EPPO Bull. 35: 434-435.

Fischer R (1954). Factors involved in drug-produced model psychoses. J. Ment. Sci. 100:623-631.

Gabarra R, Arno J (2010). Results of tomato leaf miner biological control experiments in greenhouse and open air crops in Catalonia. $1^{\text {st }}$ International PHYTOMA-Spain Encounter on Tuta absoluta. Tomato leaf miner, a serious problem in expansion. Valencia, $23^{\text {rd }}$ and $24^{\text {th }}$ March, Valencia, Barcelona, Spain. 217:66-68.

Hassan SA (1981). Mass production and utilization of Trichogramma: 2. 
Four years successful biological control of the European corn borer. Med. Fac. Landbouww. Rijksuniv. Gent. 46:417-427.

Kilic T (2010). First record of Tuta absoluta in Turkey, Phytoparasitica. 38(3):243-244.

Luna MG, Sa'nchez N, Pereyra PC (2007). Parasitism of Tuta absoluta (Lepidoptera, Gelechiidae) by Pseudapanteles dignus (Hymenoptera,Braconidae) under laboratory conditions. Environ. Entomol. 36: 887-893.

Medeiros MA, de Vilela NJ, Franca FH (2006). Technical and economic efficiency of biological control of the South American tomato pinworm in protected environment. Hortic. Bras. 24(2):180-184.

Perdikis D, Fantinou A, Garantonakis N, Kitsis P, Maselou D (2009). Studies on the damage potential of the predator Nesidiocoris tenuis on tomato plants. B. Insectol. 62(1):41-46.

Sanchez JA (2008). Zoophytophagy in the plantbug Nesidiocoris tenuis. Agric. Forest Entomol. 10:75-80.
Urbaneja A, Tapia G, Stansly P (2005). Influence of host plant and prey availability on developmental time and survivorship of Nesidiocoris tenuis (Het.: Miridae). Biocontrol Sci. Techn. 15: 513-518.

Urbaneja A, Monton H, Molla O (2009). Suitability of the tomato borer Tuta absoluta as prey for Macrolophus pygmaeus and Nesidiocoris tenuis. J. Appl. Entomol. 133:292-296.

Zar HJ (1999). Biostatistical Analysis. Fourth Edition. Prentice Hall, New Jersey-USA. p. 663. 